Please do not remove this page

RMIT

UNIVERSITY

\title{
The NBOMe hallucinogenic drug series: Patterns of use, characteristics of users and self-reported effects in a large international sample
}

Lawn, W., Barratt, M., Williams, M., Horne, A., \& Winstock, A. (2014). The NBOMe hallucinogenic drug series: Patterns of use, characteristics of users and self-reported effects in a large international sample. Journal of Psychopharmacology, 28(8), 780-788. https://doi.org/10.1177/0269881114523866 Document Version: Accepted Manuscript

Published Version: https://doi.org/10.1177/0269881114523866

Repository homepage: https://researchrepository.rmit.edu.au

CC BY-NC-ND V4.0

(C) The Author(s) 2014

Downloaded On 2023/04/26 10:35:15 +1000 
The N-BOMe psychedelic drug series: patterns of use, characteristics of users, and selfreported effects in a large international sample.

\begin{abstract}
Background: The N-BOMe compounds are a novel series of psychedelic drugs that have recently become popular in the U.S.A. and elsewhere. They are potent agonists of 5- $\mathrm{HT}_{2} \mathrm{~A}$ receptors, have a very short history of human consumption, and they are available to buy online in most countries.

Objectives: We sought to investigate the patterns of use, characteristics of users and self-reported effects.

Methods: A cross-sectional anonymous online survey of 25B-N-BOMe, 25C-N-BOMe, and 25I$\mathrm{N}-\mathrm{BOMe}$, and comparison hallucinogenic drugs, recruited as part of a larger, international study exploring patterns of drug use was used $(n=22,289)$.

Results: $2.6 \%(\mathrm{n}=582)$ of the total sample reported having ever tried one of the three N-BOMe drugs, with 25I-N-BOMe as the most popular $(n=442,2.0 \%)$. The emergence of these drugs appears to be very recent; the majority $(93.5 \%)$ of people whose last new drug tried was an NBOMe drug reported trying it in 2012. People who used an N-BOMe drug within the last year were younger than people who reported use of other hallucinogens $(2 \mathrm{C}$ drugs, magic mushrooms, or LSD) within the last year $(\mathrm{p}<0.001)$. The majority $(81.2 \%)$ of people whose last new drug tried was an N-BOMe drug either swallowed or dissolved the tab under the tongue or in the mouth, as their route of administration. This same group reported subjective effects that were very similar to the comparison serotonergic hallucinogenic drugs, but with slightly higher 'negative effects while high' and a better 'value for money'. The most common (41.7\%) source of the drugs was via a website.

Conclusions: N-BOMe drugs have emerged over the last few years, are frequently bought from the internet and are often taken orally or sublingually/bucally. They have similar effects to other hallucinogenic drugs; however, they may pose larger risks due to the limited knowledge about them, the very small doses required, and their cheapness and availability.
\end{abstract}

\title{
Introduction
}

The N-BOMe drug series are n-o-methoxybenzyl analogues of the more well-known 2C-X (e.g. $2 \mathrm{C}-\mathrm{B}$ ) family of phenethylamines (Erowid 1 ), see figure 1 . The N-BOMe series were discovered in the early 2000 s and they are psychoactive compounds belonging to the class of ringsubstituted phenethylamines, or "classical hallucinogens". These drugs (Ettrup et al., 2011) and other classical hallucinogens, including LSD (Fiorella et al., 1995), magic mushrooms, and the related $2 \mathrm{C}-\mathrm{X}$ series, are thought to act via agonism of the $5-\mathrm{HT}_{2} \mathrm{~A}$ receptors. 
Figure 1- Molecular diagrams of the 25X-N-BOMe and 2C-X drugs

\section{I-N-BOMe}<smiles>COc1cc(CCNCc2ccccc2OC)c(OC)cc1I</smiles>

25C-N-BOMe<smiles>COc1cc(CCNCc2ccccc2OC)c(OC)cc1Cl</smiles>

25B-N-BOMe<smiles>COc1cc(CCNCc2ccccc2OC)c(OC)cc1Br</smiles>

$2 \mathrm{C}-\mathrm{I}$<smiles>COc1cc(CCN)c(OC)cc1I</smiles>

$2 \mathrm{C}-\mathrm{C}$<smiles>COc1cc(CCN)c(OC)cc1Cl</smiles>

2C-B<smiles>COc1cc(CCN)c(OC)cc1Br</smiles> 
Ettrup et al. (2011) demonstrated that a radiolaballed version of 25I-N-BOMe showed high affinity for the 5-HT2A receptor in an ex vivo study in rats and a Positron Emission Tomography study in pigs. Furthermore, they showed that the 25I-N-BOMe molecules were displaceable by the $5-\mathrm{HT}_{2 \mathrm{~A}}$ antagonist ketanserin. These experiments suggest the N-BOMe drugs, like other classical hallucinogens, are agonists of the 5- $\mathrm{HT}_{2 \mathrm{~A}}$ receptors.

Human consumption of the N-BOMe drugs appears to have begun in 2010, when they became available online (Zuba et al., 2013). At the current time the N-BOMe drugs are mostly uncontrolled around the world. However, they are illegal in New Zealand, and Poland (Zuba et al., 2013) and were made temporarily illegal in the U.K. on 10/06/2013 (Home Office 1 ). The three most available N-BOMe drugs online are 25B-N-BOMe, 25C-N-BOMe, and 25I-N-BOMe (e.g.website1; website 2 ), and this article will focus on these three.

No human experimental studies have been undertaken with the N-BOMe drugs. However, anecdotal reports arising from the recreational drug using community suggest that they provoke similar effects to other "classical hallucinogens" (Erowid 2 ), which would be expected given their 5- $\mathrm{HT}_{2 \mathrm{~A}}$ receptor stimulation. People experimenting with these drugs have reported euphoria, visual and auditory hallucinations, extraordinary thoughts, and dissociations with reality $\left(\right.$ Erowid $\left._{2}\right)$.

$\mathrm{N}-\mathrm{BOMe}$ drugs are sold on blotter paper or in powder form (Erowid 3 ) and require very small doses (200-1000 $\mu \mathrm{g})$ (Zuba et al., 2013), with nasal insufflation requiring smaller amounts to sublingual administration (Erowid ${ }_{1}$ ). Given the small dose required and the lack of knowledge about these drugs, it would seem to be very easy for people to potentially take too large a dose. Furthermore, there is growing concern within amongst some hallucinogen users that $\mathrm{N}-\mathrm{BOMe}$ drugs are being sold as LSD, given that the doses and sublingual route of administration are similar (e.g. Drugs-Forum1).

There have been various media reports of death following the use of a N-BOMe drug (Erowid4) and one academic report concerning the hospitalization of an 18-year-old male after consuming 25I-N-BOMe (Rose et al., 2013).

Given that no experimental studies or quantitative analyses of N-BOMe use have taken place, the potential harms of these drugs remains largely unknown. Their extremely recent emergence, their apparent legal status, their potential to be mis-represented as LSD and their availability on the internet also augment the dangers associated with this drug series.

Therefore, this paper sought to investigate the patterns of use of these novel compounds; the characteristics of the users; the drugs' subjective effects when compared with other hallucinogenic drugs; and the prevalence of use, albeit in a self-nominating sample. We expected subjective effects to be very similar to "classic hallucinogens", such as LSD, magic mushrooms, and the $2 \mathrm{C}-\mathrm{X}$ series, and the history of use to be mostly within the last year. 


\section{Method}

The Global Drug Survey (GDS) conducts annual anonymous online surveys of drug and alcohol use in partnership with global media partners (The Guardian and Mixmag in the UK, and Fairfax Media in Australia) with onward promotion through media partner websites and social networking sites, such as Facebook and Twitter. The research tool and methods are based on previous work by the group conducted over the last decade. Accessing a large sentinel drug using population in this way allows for the rapid assessment and identification of novel drugs of abuse. Our team has successfully used this methodology to identify new drug trends before they reach the wider community (e.g. McCambridge et al., 2005; Winstock et al., 2001). Extensive discussion of the methods used including their utility, validity, and limitations are discussed $\mathrm{n}$ previously published articles (Winstock et al., 2001; Winstock et al., 2011; Winstock et al., 2012; Winstock \& Barratt 2013).

When compared with traditional epidemiological criteria for public health surveillance, this datacollection method has significant limitations. For instance, it recruits from a self-nominating population and it relies upon self-reported data concerning substances whose true composition is uncertain. Nonetheless, this method is very useful when determining new drug trends and the associated harms and effects.

In this particular study, basic information was collected to identify the demographic using NBOMe drugs including: age, currency used, and drug use history. We used 'currency used' as a proxy measure of country of residence because a large amount of 'country of residence' data was missing. In order to quantify the subjective effects of the N-BOMe drugs and compare them against similar hallucinogenic drugs, respondents were asked to name the last new drug that they tried and answer questions about their experience. Specifically, they were asked to rate, from 0 to 10: 'the pleasurable high', 'the strength of the effect', 'the negative effects while high', 'the comedown after use', 'the urge to use more of the drugs when using', 'the value-for-money', and 'the risk of harm following a session of use'. Furthermore, they were asked how the drug was administered, how the drug was sourced, how long the effects lasted, how long it took for 'peak effects' to occur after a single dose, and what the 'predominant effect' of the drug was.

In order to assess N-BOMe, and other hallucinogen use, absolute numbers and percentages of people reporting having ever used a drug, use in the last 12 months, and use in the last month were collected. To determine the recency of N-BOMe use, those whose last new drug was an NBOMe were asked which year they had tried it. Furthermore, the proportion of people who reported ever having used a drug and who stated that drug was their most recently tried new drug was calculated. A chi-square test was used to determine whether there were differences in the proportions of males and females within the N-BOMe user group and a group of comparison hallucinogen users. A t-test was used to test whether there was a significant difference in age between these two groups. Predominant effect, route of administration, duration of effect, time until peak effect, and subjective effects of the N-BOMe drugs were assessed by consideration of absolute numbers and percentages. 
Due to the nature of data collection through an online survey, it was inevitable that missing data would occur. The majority of the results are reported simply as absolute numbers and percentages, e.g. $\mathrm{W}$ people $(\mathrm{X} \%)$ stated that $\mathrm{N}-\mathrm{BOMe}$ was their last new tried drug and $\mathrm{Y}(\mathrm{Z} \%)$ of those tried it in 2012. It was common for people to provide one piece of information, e.g. the last new drug they tried, but not a secondary piece of information, e.g. which year they tried it in. In this situation, we have used 'valid' percentages, that is the proportion of respondents who reported a specific thing out of those who reported something; the percentages do not include those who did not provide specific information. For instance, if someone reported N-BOMe as their last new drug tried but did not report the year they tried it in, they would not contribute to the denominator of the percentage calculation.

\section{Results}

\section{Whole sample demographics}

The Global Drug Survey went online in November 2012 and closed in December 2012. A total of 22,289 responses were collected. 7,360 (33.9\%) respondents were from the UK, 2,164 $(10.0 \%)$ were from the Euro-Zone, $3,756(17.3 \%)$ were from the U.S.A., $618(2.9 \%)$ were from Canada, and 7,784 (35.9\%) were from Australia (using local currency as a proxy for country).

Most (68.6\%) respondents were male and the mean age was 31.4 years (standard deviation (SD) $=12.4$, range $16-100)$. The male age mean was $30.9(\mathrm{SD}=12.6)$ and the female age mean was $30.9(\mathrm{SD}=11.8)$.

\section{Hallucinogenic drug use}

The sample consisted of experienced users of hallucinogenic drugs; $39.4 \%$ of respondents reported having ever used LSD, $43.1 \%$ magic mushrooms, and $26.0 \%$ ketamine. Last month use for these three hallucinogenic drugs was similar in the global sample, at around 5\%, see table 1 for the prevalence statistics.

$582(2.6 \%)$ of respondents reported having ever used any one of the three N-BOMe drugs. The most popular of the three was $25 \mathrm{I}-\mathrm{N}-\mathrm{BOMe}(\mathrm{n}=442,2 \%)$, followed by $25 \mathrm{~B}-\mathrm{N}-\mathrm{BOMe}(\mathrm{n}=267$, $1.2 \%)$, followed by $25 \mathrm{C}-\mathrm{N}-\mathrm{BOMe}(\mathrm{n}=65,0.8 \%)$. Because the separate drugs' effects were similar, their chemical structures alike, and very little is known about them, even as a group of drugs, analysis will continue with them grouped together as N-BOMe drugs. 
Table 1 - Prevalence of hallucinogenic drug use

\begin{tabular}{|c|c|c|c|c|c|c|}
\hline & \multicolumn{2}{|c|}{ Ever used } & \multicolumn{2}{|c|}{ Last 12 months use } & \multicolumn{2}{|c|}{ Last month use } \\
\hline & $\mathrm{N}$ & $\%$ & $\mathrm{~N}$ & $\%$ & $\mathrm{~N}$ & $\%$ \\
\hline LSD & 8774 & 39.4 & 3340 & 15 & 1149 & 5.2 \\
\hline Magic mushrooms & 9604 & 43.1 & 3587 & 16.1 & 1180 & 5.3 \\
\hline Ketamine & 5784 & 26.0 & 2505 & 11.2 & 1185 & 5.3 \\
\hline 2C-I & 1054 & 4.7 & 419 & 1.9 & 65 & 0.3 \\
\hline 2C-B & 1866 & 8.4 & 879 & 3.9 & 242 & 1.1 \\
\hline 2C-E & 777 & 3.5 & 338 & 1.5 & 58 & 0.3 \\
\hline 2C-C & 180 & 0.8 & 91 & 0.4 & 18 & 0.1 \\
\hline 25B-N-BOMe & 65 & 0.3 & 47 & 0.2 & 24 & 0.1 \\
\hline 25C-N-BOMe & 267 & 1.2 & 233 & 1.0 & 112 & 0.5 \\
\hline 25I-N-BOMe & 442 & 2.0 & 406 & 1.8 & 177 & 0.8 \\
\hline Any N-BOMe drug & 582 & 2.6 & 526 & 2.4 & 189 & 0.8 \\
\hline Any 2C-X drug & 2526 & 11.3 & 1263 & 5.7 & 348 & 1.6 \\
\hline
\end{tabular}

\section{Recent N-BOMe drug use}

$526(2.3 \%)$ of respondents reported having used any one of the three N-BOMe drugs in the last 12 months and $189(0.8 \%)$ reported having used one in the last month. This former percentage suggests that the majority of people who have ever used this drug have used it in the last 12 months.

This is corroborated by the data concerning which drug was tried for the first time most recently and which year it was tried in, see figure 2. Almost all (93.5\%) people whose most recently tried new drug was an N-BOMe drug had tried it in 2012, whereas $56.6 \%$ of people whose most recently tried new drug was a $2 \mathrm{C}-\mathrm{X}$ drug had tried it in 2012, and the percentages were smaller still for LSD (45.6\%), magic mushrooms (42.9\%), and ketamine (35.8\%). 
Furthermore, the percentage of lifetime N-BOMe users for whom an N-BOMe drug was also their most recently tried new drug was high $(40.9 \%)$, and higher than that for LSD $(14.3 \%)$, magic mushrooms (13.5\%), ketamine (18.9\%) and the 2C-X drugs (26\%) These results strongly suggest that $\mathrm{N}-\mathrm{BOMe}$ drugs have recently become available and are attracting a larger proportion of new users, compared to lifetime users, than other similar hallucinogenic substances.

Figure 2 - The year in which the last new drug was tried.

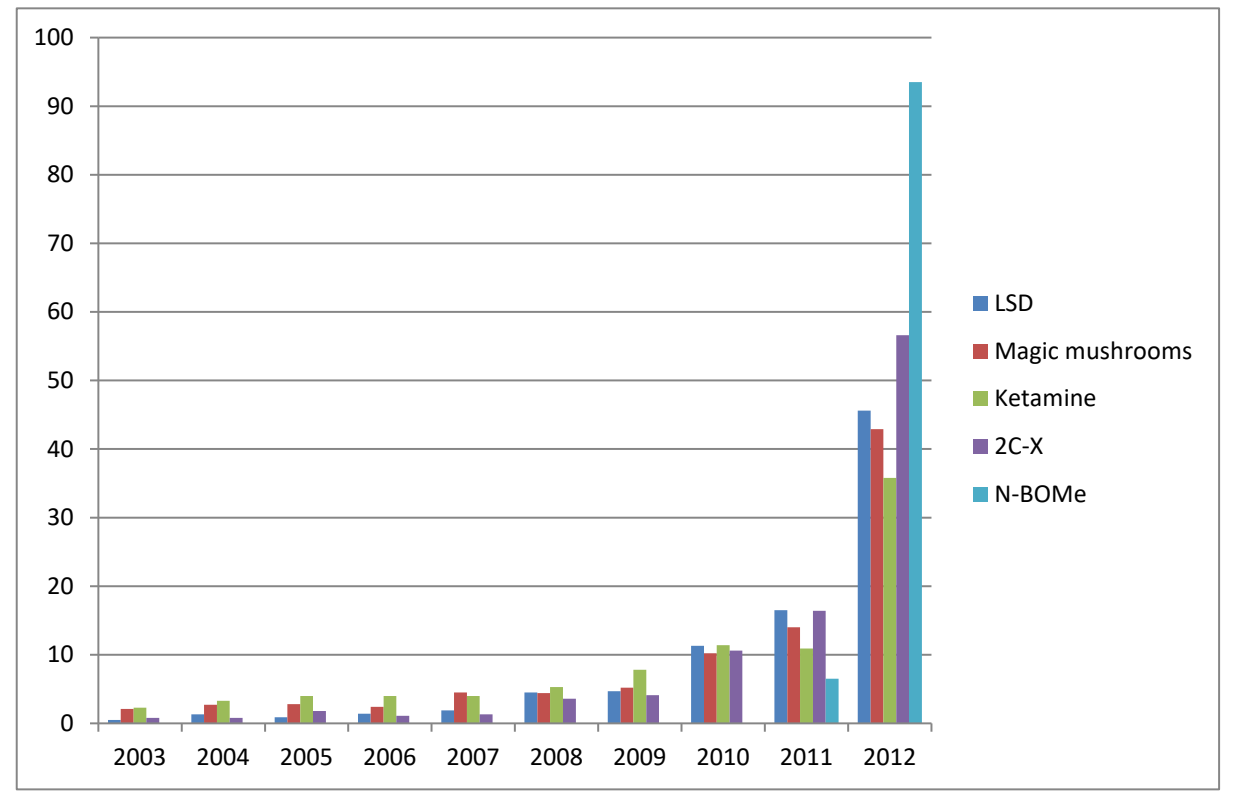

\section{Demographics of N-BOMe users}

A 'user' is defined as anyone who has used a drug in the last 12 months. A majority ( $\mathrm{n}=296$; $56.7 \%$ ) of N-BOMe users used U.S.A. dollars and were therefore likely to come from the U.S.A. $21.3 \%(n=111)$ of users used British Pounds, $10.2 \%(n=53)$ used Euros, 9.8\% $(n=51)$ used Australian Dollars, and 2.1\% $(\mathrm{n}=11)$ used Canadian Dollars. This distribution was significantly different from that of non-N-BOMe-users $\left(\chi^{2}(4)=606.99, p<0.001\right)$; however due to the selfnominating sample, this result should be considered with caution (see discussion). The distribution of currencies was similar for LSD users and magic mushroom users, where the largest portion of users used U.S. dollars (36.8\% and $43.4 \%$ respectively). However, for the $2 \mathrm{C}$ - 
$\mathrm{X}$ drugs and ketamine, the largest proportion of users used Pounds $(46.1 \%$ and $62.2 \%$ respectively).

To compare the gender ratio and age of $\mathrm{N}-\mathrm{BOMe}$ users with other drug users, two groups were analysed: people who reported using an N-BOMe drug but not a $2 \mathrm{C}-\mathrm{X}$ drug, LSD or magic mushrooms (classic hallucinogen group) in the last year $(\mathrm{n}=77)$ and people who reported using a 2C-X drug, LSD or magic mushrooms but not an N-BOMe drug in the last year $(\mathrm{n}=4954)$. Most respondents who reported using an N-BOMe drug in the last year had also used a classic hallucinogen in the last year $(n=449)$.

The proportion of males in the N-BOMe group (95.9\%) was significantly larger than in the classic hallucinogen group $(77.5 \%)\left(\chi^{2}(1)=14.079, p<0.001\right)$. The average age of the N-BOMe user group was $21.5(\mathrm{SD}=5.3)$ and the average age of the classic hallucinogen group was 26.2 $(\mathrm{SD}=8.7)$. Without assuming equal variances in the groups, as Levene's test was significant, these ages were significantly different $\left(t_{(80.540)}=5.908, p<0.001, r=0.550\right)$.

Description by those whom an N-BOMe drug was 'the last new drug tried'

In order to produce abuse liability ratings and subjective effects of various drugs, respondents were asked to name the last new drug that they tried and were asked about the effects of it. Therefore, this allows a comparison of the effects of $\mathrm{N}$-BOMe drugs against other similar hallucinogens' (LSD, magic mushrooms, ketamine, and any 2C-X) effects to be made, all of which were described by people where that drug was the last new drug they had tried.

The following results are from a subpopulation of the sample who gave information on their last new drug tried and who listed it as an N-BOMe drug $(n=233,1.3 \%)$, LSD $(n=1130,6.5 \%)$, magic mushrooms $(n=1157,6.6 \%)$, ketamine $(n=993,5.7 \%)$, or a 2 - $\mathrm{X}$ drug $(n=615,3.5 \%)$ when completing this survey.

The prevalence of lifetime hallucinogenic drug use within the N-BOMe as last new drug tried group was large. Most $(72.2 \%, \mathrm{n}=169)$ of them had used LSD, $65.4 \%(\mathrm{n}=153)$ magic mushrooms, $45.2 \%(\mathrm{n}=108)$ any $2 \mathrm{C}-\mathrm{X}$ drug, and 33.8\% $(\mathrm{n}=79)$ ketamine. In fact, $88.9 \%(\mathrm{n}=$ 208) of this group had tried at least one of these other hallucinogenic drugs. This experience with hallucinogenic drugs makes their ratings of N-BOMe drugs somewhat more trustworthy, as their ratings will be made with the knowledge of what other hallucinogenic drugs feel like.

The amount of experience of hallucinogenic drugs and MDMA was different between the last new drug tried groups. The last new drug as an N-BOMe drug or a $2 \mathrm{C}-\mathrm{X}$ drug groups appeared to have increased experience of hallucinogens, including more obscure drugs, compared with the other groups. As seen above, most of the N-BOMe group had tried the other hallucinogens investigated and 64.1\% $(n=150)$ had tried MDMA in their lifetime, while $70.6 \%(n=434)$, $65.4 \%(n=464), 63.6 \%(n=391)$, and $84.4 \%(n=519)$ of the $2 C-X$ group had tried LSD, magic
Commented [MJB5]: Provide the n's for each group

Commented [MJB6]: Provide the percentage male for each group as well.

Commented [MJB7]: I like what you've done with this! 
mushrooms, and ketamine respectively. These groups both had over $4 \%$ of group members reporting 4-ACO-DMT and 5-MEO-DMT lifetime use, which represents more obscure hallucinogenic drug use.

Comparatively, $35.9 \%(n=415), 22.7 \%(n=263)$, and $40.4 \%(n=468)$ of the magic mushroom group had tried LSD, ketamine, and MDMA respectively. The percentages for the LSD and ketamine groups were similar to the magic mushroom group. Furthermore, these groups all had less than $1.5 \%$ of group members reporting 4-ACO-DMT and 5-MEO-DMT lifetime use.

\section{All five groups had a similar age of first use for these drugs. For instance, all groups had a mean age of first use of MDMA between 19 and 21.}

Almost all (93.5\%) respondents whose last new drug tried was an N-BOMe drug stated that its 'predominant effect' was 'psychedelic: LSD or ketamine-like', while $2.2 \%$ described it as 'empathogen: MDMA-like', $1.3 \%$ 'stimulant: cocaine-like' and $0.4 \%$ 'cannabis-like'. A further $2.6 \%$ of this group described it as 'other', in that they thought its predominant effect could not be described by these categories.

When asked about route of administration for N-BOMe drugs, the majority $(n=190 ; 81.2 \%)$ of the group reported 'swallowed' or 'other'. When investigating what 'other' referred to, all of the responses were 'sublingual', 'buccal' (between the gum and cheek), 'tab on tongue', or something very similar. Therefore, it can be concluded that putting a tab (a small piece of paper with a drop of liquid drug on it) in the mouth, below the tongue, or swallowed, is the most common route of administration. However, a minority $(17.9 \%)$ of people reported snorting the drug.

The most common source of N-BOMe drugs was from a website $(n=99,41.7 \%)$. The second most common source was a friend $(\mathrm{n}=92,39.7 \%)$, and the third most common from a 'dealer' $(\mathrm{n}=37,15.9 \%)$.

The variation in time to peak effect was large, see figure 3. Two people reported a peak effect with 5 minutes and two people reported a peak effect within 5 hours. The modal time to reach peak effect was two hours $(n=57,24.7 \%)$, which was the same for LSD $(n=264 ; 23.9 \%)$. However, the 2C-X drugs had a faster modal onset of 90 minutes $(\mathrm{n}=115,19.1 \%)$. Magic mushrooms had a modal onset of 60 minutes $(n=261 ; 23.3 \%)$ and ketamine had a modal onset of 5 minutes $(n=204 ; 21.3 \%)$. Those who snorted the N-BOMe drug appeared to have a smaller time to peak effect, with a modal time of 45 minutes $(n=9,21.4 \%)$, than those who swallowed it or took it sublingually, with a modal time of 2 hours $(n=52,27.5 \%)$. Furthermore, $19.0 \%(n=$ 8 ) of those who snorted it reported a peak effect by 20 minutes or less, which was significantly larger than the $2.1 \%(n=4)$ of those who swallowed or took it sublingually $\left(\chi_{(1)}^{2}=19.874\right.$, $p<.001)$.
Commented [W8]: I put this in so I could discuss the differences in drug experience between the groups that might be important in subjective ratings. However, I realise that it is quite long and clumpy. I didn't include the ketamine, LSD groups because it would have got even longer. And a table including all of this information would have 32 rows! Could we just sum up without reporting all of the data? 
Figure 3- Time to reach peak effect with N-BOMe drugs

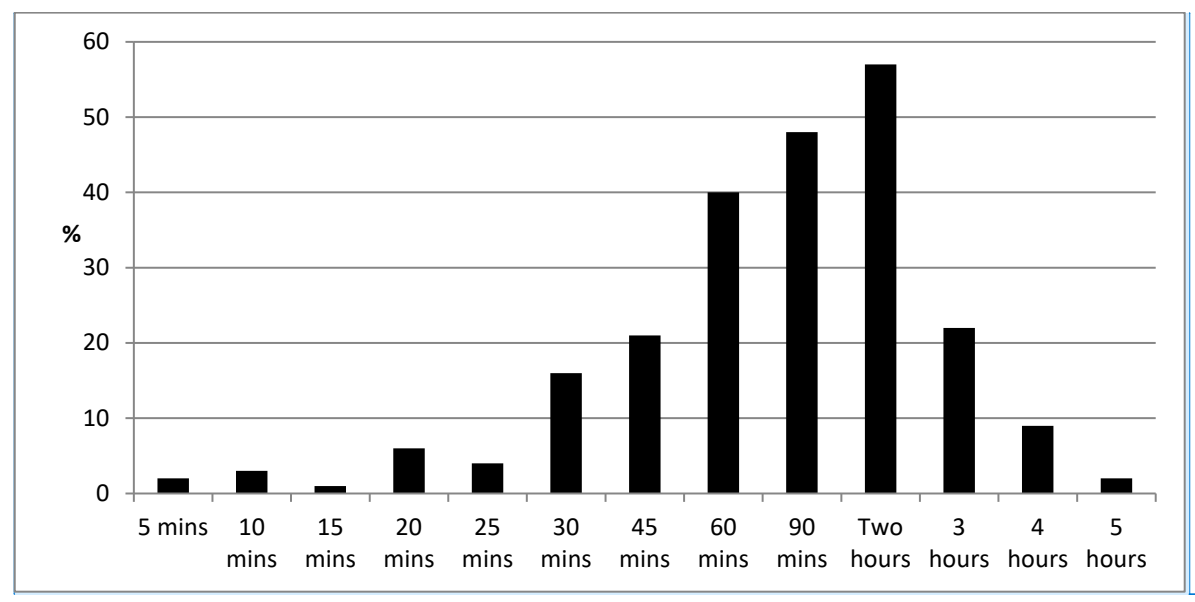

Commented [MJB10]: change "\% of people" to "\%"

There was a large variation in the duration of effect from a single dose of an N-BOMe drug, with a range from 60 minutes to more than 24 hours, see fig 4 . The modal duration was 6 hours $(\mathrm{n}=$ $64,27.5 \%$ ) and $95 \%$ of the respondents reported a duration of effect between 3 hours and 13 hours. Those who snorted the drug and those who swallowed it or took it sublingually also showed modal durations of 6 hours $(n=13,31 \%$ and $n=51,26.7 \%$ respectively). However, $21.4 \%(n=9)$ of those who snorted it reported a duration of effect of less than 6 hours; which was more than the $15.7 \%(n=30)$ of those who swallowed it or took it sublingually, but not significantly so $\left(\chi^{2}(1)=0.809, p=0.368\right)$.

Comparatively, the modal duration reported by those whose last new drug was LSD was 8 hours $(n=214,19.1 \%)$, for magic mushrooms it was 6 hours $(n=268,23.5 \%)$, for any $2 \mathrm{C}-\mathrm{X}$ drug it was 6 hours $(\mathrm{n}=121,19.9 \%)$, and for ketamine it was 60 minutes $(\mathrm{n}=24.1,24.9 \%)$. 
Figure 4 - Duration of effect of N-BOMe drugs

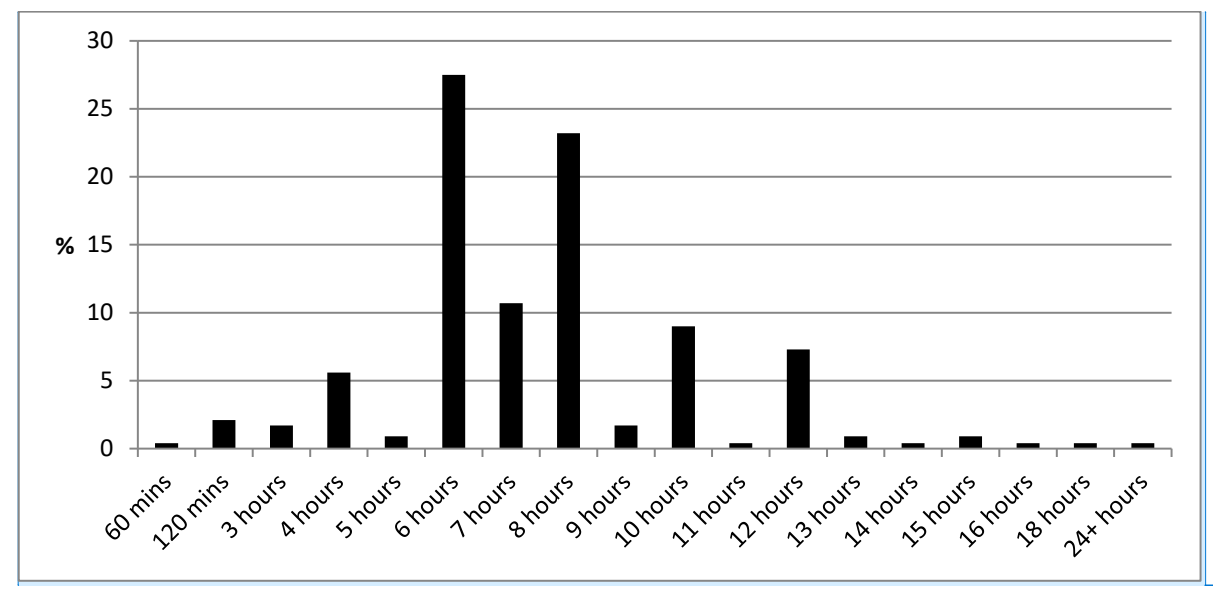

Commented [MJB11]: change "\% of people" to "\%"

Table 2 contains the ratings concerning the subjective effects of $\mathrm{N}-\mathrm{BOMe}$ drugs, $2 \mathrm{C}-\mathrm{X}$ drugs, LSD, magic mushrooms and ketamine.

The N-BOMe drugs were rated as giving the third most pleasurable high with $6.5(\mathrm{SD}=2.0)$. LSD was rated as giving the most pleasurable high with $7.4(\mathrm{SD}=2.3) .55 .6 \%$ and $46.4 \%$ of people rating LSD and magic mushrooms rated them as giving a pleasurable high between 8 and 10 , respectively. Whereas, $32.5 \%$ of people rating the N-BOMe drugs gave scores between 8 and 10. Ketamine had the lowest pleasurable high with $5.27(\mathrm{SD}=2.7)$ and only $20.1 \%$ of people gave it a score between 8 and 10 . 
The N-BOMe drugs were rated as having the second strongest effect with $7.2(\mathrm{SD}=2)$, after LSD with $7.6(\mathrm{SD}=2.1)$. However, LSD $(59.7 \%)$, magic mushrooms $(49.7 \%)$, and ketamine $(50.2 \%)$ all had higher proportions of people giving them a strength of effect between 8 and 10 than the N-BOMe drugs (47.0\%). The $2 \mathrm{C}$-X drugs had the lowest proportion of people rating the strength between 8 and 10 with 42.5\%. Unsurprisingly, those who administered an N-BOMe drug by snorting it reported a significantly stronger effect of $7.9(\mathrm{SD}=1.8)$ than those who administered by swallowing it or taking it sublingually with $7.1(\mathrm{SD}=2.1)(t=2.434, p<0.05$, $r=0.16)$.

In terms of value for money, the N-BOMe drugs were rated the best with 7.9 (SD = 2.4). Furthermore, they had the largest proportion of people rating them as having a value of money between 8 and 10 with $65.1 \%$.

However, the N-BOMe drugs were rated as having the second greatest negative effects while high with $3.5(\mathrm{SD}=2.4)$; ketamine was rated worse with $3.7(\mathrm{SD}=2.9)$ and the three classical hallucinogens were rated as least negative. The N-BOMe drugs also had the smallest proportion of people giving a rating of 0 and $0-3$ for negative effects while high with $11.7 \%$ and $52.8 \%$, respectively.

Furthermore, the N-BOMe drugs were rated as having the second worst comedown with 2.7 (SD $=2.3)$; LSD was rated as worse with $3.2(\mathrm{SD}=2.8)$. These two also had the smallest proportions of people giving a rating of 0 for the subsequent comedown: LSD with $20.6 \%$ and the N-BOMe drugs with $20.8 \%$. Magic mushrooms had the least bad comedown with a score of 2.1 ( $\mathrm{SD}=$ 2.2).

The N-BOMe drugs were also rated as having the second highest risk of harm following a session of use with $2.5(\mathrm{SD}=2.6)$; ketamine was rated as the worst with $3.3(\mathrm{SD}=3.0)$. Magic mushrooms were rated as producing the least harm following use with $1.8(\mathrm{SD}=2.4)$.

On the other hand, the N-BOMe drugs and magic mushrooms shared the lowest rating for urge to use more, with $1.3(\mathrm{SD}=2.6, \mathrm{~N}-\mathrm{BOMe} ; \mathrm{SD}=2.2$, magic mushrooms). These two also had the largest proportion of people rating their urge to use more as 0 with $56.0 \%$, for the N-BOMe drugs, and $59.5 \%$, for magic mushrooms. 


\begin{tabular}{|c|c|c|c|c|c|c|c|c|c|c|c|c|c|c|}
\hline \multirow[b]{2}{*}{ Drug } & \multicolumn{2}{|c|}{$\begin{array}{l}\text { The } \\
\text { pleasurable } \\
\text { high }\end{array}$} & \multicolumn{2}{|c|}{$\begin{array}{l}\text { Strength } \\
\text { of the } \\
\text { effect }\end{array}$} & \multicolumn{2}{|c|}{$\begin{array}{l}\text { Negative } \\
\text { effects } \\
\text { when high }\end{array}$} & \multicolumn{2}{|c|}{$\begin{array}{l}\text { Comedown } \\
\text { after use }\end{array}$} & \multicolumn{2}{|c|}{$\begin{array}{l}\text { Value for } \\
\text { money }\end{array}$} & \multicolumn{2}{|c|}{$\begin{array}{l}\text { Risk of } \\
\text { harm } \\
\text { following a } \\
\text { session of } \\
\text { use }\end{array}$} & \multicolumn{2}{|c|}{$\begin{array}{l}\text { Urge to use } \\
\text { more of } \\
\text { the drugs } \\
\text { when using }\end{array}$} \\
\hline & Mean & SD & Mean & SD & Mean & SD & Mean & SD & Mean & SD & Mean & SD & Mean & SD \\
\hline N-BOMe & 6.5 & 2.0 & 7.2 & 2.1 & 3.5 & 2.4 & 2.7 & 2.3 & 7.9 & 2.6 & 2.5 & 2.1 & 1.3 & 2.4 \\
\hline $2 C-X$ & 6.3 & 2.3 & 6.9 & 2.1 & 2.8 & 2.7 & 2.5 & 2.2 & 6.8 & 2.2 & 1.8 & 2.3 & 1.6 & 2.6 \\
\hline LSD & 7.4 & 2.3 & 7.6 & 2.1 & 2.8 & 2.7 & 3.2 & 2.8 & 7.7 & 2.6 & 2.0 & 2.3 & 1.5 & 2.6 \\
\hline $\begin{array}{l}\text { Magic } \\
\text { Mushrooms }\end{array}$ & 6.8 & 2.5 & 7.1 & 2.3 & 2.9 & 2.8 & 2.1 & 2.4 & 7.3 & 2.4 & 1.8 & 2.2 & 1.3 & 2.7 \\
\hline Ketamine & 5.3 & 2.7 & 7.2 & 2.2 & 3.7 & 2.9 & 2.6 & 2.5 & 5.6 & 3.0 & 3.3 & 3.0 & 2.9 & 2.9 \\
\hline $\begin{array}{l}\text { N-BOMe } \\
\text { (never tried } \\
\text { hallucinogens) }\end{array}$ & 6.2 & 2.3 & 7.7 & 2.0 & 4.2 & 2.2 & 3.2 & 2.6 & 7.6 & 2.3 & 2.9 & 2.6 & 1.2 & 1.9 \\
\hline $\begin{array}{l}\text { N-BOMe } \\
\text { (tried other } \\
\text { hallucinogens) }\end{array}$ & 6.5 & 2.0 & 7.2 & 2.1 & 3.5 & 2.4 & 2.7 & 2.3 & 7.9 & 2.5 & 2.4 & 2.6 & 1.3 & 2.1 \\
\hline
\end{tabular}

\section{Discussion}

This is the first report on patterns of use and associated psychological effects of the highly novel $\mathrm{N}-\mathrm{BOMe}$ drug series in a human population. We surveyed 582 people who reported having ever used one of the three N-BOMe drugs, with 25I-N-BOMe the most popular $(n=442)$. The popularity of these drugs is a very recent phenomenon, with $93.5 \%$ of those whose last new drug tried was an N-BOMe drug tried it in 2012. Furthermore, people who had used an N-BOMe drug but not a classical hallucinogen in the last year were younger and more likely to be male than people who had used a classical hallucinogen but not an N-BOMe drug in the last year. N-BOMe drugs were mostly swallowed or taken sublingually/bucally $(81.2 \%)$, though a minority $(17.9 \%)$ snorted them. 
In terms of subjective effects, $93.5 \%$ of the N-BOMe as last new drug tried group described its predominant effect as 'psychedelic'. Furthermore, their 'pleasurable high', 'strength of effect', 'comedown after use', and 'urge to use more' ratings were very similar to the serotonergic hallucinogenic drugs. However, their 'negative effects while high' and 'risk of harm following use' ratings were higher than those of the serotonergic hallucinogens and were more similar to the glutamatergic hallucinogen ketamine. Interestingly, the N-BOMe drugs were rated as the best value for money.

Our finding that the $\mathrm{N}-\mathrm{BOMe}$ as last new drug tried group mostly tried it in 2012 supports the information on Erowid, which holds reports of N-BOMe use from 2011 onwards (Erowid ( $_{1}$. $40.9 \%$ of lifetime users, who did report a last new drug tried, reported an N-BOMe drug as their last new drug tried. It is possible, though unlikely, that the $59.1 \%$ of them who didn't report an $\mathrm{N}-\mathrm{BOMe}$ drug as their last new drug tried could have tried it before 2011. This study implies that the N-BOMe drugs have emerged very recently and rapidly.

The geographical distribution of N-BOMe users, using currency as a proxy, should be interpreted cautiously. Although we found there were significantly more N-BOMe users from the U.S.A. than in the non-N-BOMe user group, this may well be due to the different ways of recruiting respondents from different countries. Across the whole survey, the mean age of respondents from the U.S.A. was much lower than the mean age of respondents from Australia. Hence, this difference could have driven the different proportions of N-BOMe users from these countries. Further investigation of $\mathrm{N}-\mathrm{BOMe}$ users is needed to confirm these findings.

Nearly half of the N-BOMe as last drug group sourced their drug from a website. This is unsurprising given their apparent legality, as websites can legally advertise the drugs as 'not for human consumption' chemicals (e.g. website 1 ). This widespread availability on the internet and easy transportation, given the small doses required, may result in a simple transaction, which could be preferable to buying drugs from a traditional dealer for some drug users. Furthermore, this availability could be involved in the claims that N-BOMe drugs are being sold as LSD (Drugs-Forum 1 ), as dealers could potentially buy N-BOMe drugs cheaply and easily from the internet and make profits marketing it as LSD.

The fact that a large majority of people reported 'swallow' or 'other' (which equated to 'sublingual', 'buccal', or something very similar) as their route of administration for N-BOMe drugs is likely a result of their most common form being tabs. Alternatively, users could wrap up powder form N-BOMe drugs and swallow them, but our data does not permit us to differentiate these different routes of administration within the 'swallow' category. A minority of people reported 'snorting' as the way they consumed the drug. As with many other drugs, the desired effects of $\mathrm{N}-\mathrm{BOMe}$ drugs require smaller doses using this route of administration (Erowid ${ }_{1}$ ) and therefore the danger of over-dosing is higher, and should potentially be advised against.

The variability in the time to reach peak effect reported by the N-BOMe as last new drug group was large, ranging between 5 minutes to 5 hours. This is probably a consequence of some people

Commented [MJB13]: Ive removed this reference to Silk Roadpaper still needs to be submitted and reviewed. Can't really cite it yet. 
snorting the drug, which led to a quicker onset and others administering it sublingually, or a similar route, which led to a slower onset. The modal time to reach peak effect was 2 hours, which was the same for LSD, demonstrating the similar mechanism of action and sublingual route of administration.

The modal duration of effect from a single dose for any N-BOMe drug was 6 hours, which was the same as for magic mushrooms and the $2 \mathrm{C}-\mathrm{X}$ drugs. These durations were slightly smaller than that for LSD, which had a modal duration of 8 hours and has been found to produce effects for over 24 hours at large doses (Klee et al., 1961). Those who snorted an N-BOMe drug appeared to have a shorter duration than those who swallowed it or took it sublingually, though there was no significant difference between the proportions that reported a duration of less than 6 hours.

As predicted, the N-BOMe drugs have a very similar profile of subjective effects compared with the classical hallucinogens of LSD and magic mushrooms, with some less attractive aspects. The vast majority of people reported a predominant effect that was 'psychedelic', which was expected given the N-BOMe drugs' agonism of the 5-HT2A receptors (Ettrup et al., 2011) and the well-substantiated claim that hallucinogenic effects are mediated through activity at these receptors (e.g. Marek \& Aghajanian, 1996). Furthermore, the 'pleasurable high', 'strength of effect', 'comedown after use', and 'urge to use more' ratings were similar for the four serotonergic hallucinogens compared in this study. This conforms to the idea that serotonergic hallucinogenic drugs have low abuse liabilities (Morgenstern et al., 1994), with very little urge to use more. On the other hand, ketamine, primarily a glutamatergic drug, had higher 'urge to use more' ratings, which is concordant with reports of dependence (Morgan \& Curran, 2012). Additionally, the 'comedown after use' ratings were low for all of the hallucinogenic drugs investigated, which could also play into their low abuse liabilities, as the desire to escape unpleasant after-effects would be minimal.

However, N-BOMe drugs did have a higher rating for 'negative effects while high' in comparison to the other serotonegic hallucinogenic drugs, and the rating was more similar to that of ketamine. The reasons for these larger negative effects are not known. However, along with the very important fact that these drugs are highly novel and their harms have not been documented yet, this information could be used to dissuade people from using them instead of other traditional hallucinogens, such as LSD and magic mushrooms, where the harms are thought to be relatively small (Nutt et al., 2010).

One alternative explanation for this higher 'negative effects while high' rating for N-BOMe drugs could be a difference between those rating N-BOMe drugs and those rating other hallucinogenic drugs. It is likely that those whose last new drug tried was an N BOMe drug are more experimental drug users than those whose last new drug tried was a traditional drug, like magie mushroemswas found that those whose last new drug tried was an N-BOMe drug were more experienced with a variety of hallucinogenic drugs than those whose last new drug tried was magic mushrooms, LSD or ketamine. With heavier and more experimental drug use, one might expect different ratings, for instance more positive ratings because heavier users might 
generally enjoy drug use more. This was somewhat substantiated in that those whose last new drug was an N-BOMe and had tried one of the other comparison hallucinogens rated the NBOMe drugs slightly more pleasurable and with a slightly smaller negative effect while high. However, this effect is very small, so it is unlikely that a difference in previous drug use experience could account for the differences in ratings of the hallucinogens investigated here.

Interestingly, the N-BOMe drugs were rated as the best value for money amongst the hallucinogenic drugs investigated. This is probably a consequence of their apparent legal status and availability online, where prohibition is thought to drive the price of an illegal drug up (Schulhofer et al.,1994). This price situation is somewhat undesirable given that it would probably be less harmful for people to take traditional hallucinogens than these relatively poorly understood N-BOMe drugs.

This study found a relatively low prevalence of N-BOMe use in comparison with other classic hallucinogens. However, due to the self-nominating sample used, one cannot draw conclusions about prevalence in the population. With the temporary ban in the U.K., a fall in use and a rise in price may be expected. Freeman et al. (2012) found that $80 \%$ of mephedrone users used less after its ban in the U.K. and 95\% reported an increase in price. However, Winstock et al.(2010) reported that soon after the ban, use remained stable but the price had increased. Hence, the temporary illegality's effect on N-BOMe use in the U.K. is unclear. The 2014 Global Drug Survey will provide data concerning the differential trends of $\mathrm{N}-\mathrm{BOMe}$ use in countries that illegalised the drugs and those that didn't.

\section{Limitations}

This is the first, and relatively large, quantitative study of $\mathrm{N}-\mathrm{BOMe}$ drug use ever conducted. However, the respondents in this survey may not be representative of $\mathrm{N}-\mathrm{BOMe}$ drug users as a whole, given that the sample was self-nominating. And as always, the findings are limited by the self-reported nature of the data and the fact that there is no way to confirm the true composition of the substance consumed. Furthermore, high-levels of poly-drug use is expected and no data concerning the dose of the drug consumed or setting during the experience was collected. These limitations and others have been discussed more fully elsewhere (e.g. e.g. McCambridge et al., 2005; Winstock et al., 2001; Winstock et al., 2011). However, this group has previously shown that self-report studies in this population can be a valid and effective tool for describing the effects and emergence of novel drugs (e.g. Winstock et al., 2011).
Commented [MJB14]: this is very interesting - NBOMe last time users might be more experimental or more experienced. But we can test for this can't we... e.g. compare number of different drugs tried by last use NBOMe versus the others, also age of first use? 


\section{Conclusions}

The rapid, yet limited, emergence of N-BOMe drugs around the world, and especially in the U.S.A., is very likely a consequence of the ease of avaibility provided by the internet. These drugs seem to have a very similar profile of effects to other serotonergic hallucinogenic drugs and are most frequently consumed sublingually or via a similar method.

$\mathrm{N}-\mathrm{BOMe}$ drugs have an extremely short history of human consumption, have been linked to deaths (Erowids) and hospitalizations (Rose et al., 2013), and have a higher rating for 'negative effects while high' than similar drugs. Therefore, people should be dissuaded from using these drugs until further evidence has been accrued, and information about the relative safety of traditional, and purportedly more enjoyable, serotonergic hallucinogenic drugs should be disseminated.

\section{References}

Drugs forum 1 : http://www.drugs-forum.com/forum/showthread.php?t=204870

Ettrup, A., Hansen, M., Santini, M. A., Paine, J., Gillings, N., Palner, M., ... \& Knudsen, G. M. (2011). Radiosynthesis and in vivo evaluation of a series of substituted 11C-phenethylamines as 5-HT2A agonist PET tracers. European journal of nuclear medicine and molecular imaging, 38(4), 681-693.

Erowid http://www.erowid.org/chemicals/nbome/

Erowid $_{2}$ http://www.erowid.org/experiences/subs/exp NBOMe Series.shtml

Erowid $_{3}$ http://www.erowid.org/chemicals/nbome/nbome dose.shtml

Erowid 4 http://www.erowid.org/chemicals/2ci nbome/2ci nbome death.shtml

Erowidshttp://www.erowid.org/chemicals/2ci_nbome/2ci_nbome_death.shtml

Fiorella, D., Rabin, R. A., \& Winter, J. C. (1995). The role of the 5-HT2A and 5-HT2C receptors in the stimulus effects of hallucinogenic drugs I: Antagonist correlation analysis. Psychopharmacology, 121(3), 347-356. 
Freeman, T. P., Morgan, C. J., Vaughn-Jones, J., Hussain, N., Karimi, K., \& Curran, H. V. (2012). Cognitive and subjective effects of mephedrone and factors influencing use of a 'new legal high'. Addiction, 107(4), 792-800.

Home Office 1 https://www.gov.uk/government/news/nbome-and-benzofury-to-be-banned

Klee, G. D., Bertino, J., Weintraub, W., \& Callaway III, E. N. O. C. H. (1961). The influence of varying dosage on the effects of lysergic acid diethylamide (LSD-25) in humans. The Journal of Nervous and Mental Disease,132(5), 404-409.

Marek, G. J., \& Aghajanian, G. K. (1996). LSD and the phenethylamine hallucinogen DOI are potent partial agonists at 5-HT2A receptors on interneurons in rat piriform cortex. Journal of Pharmacology and Experimental Therapeutics, 278(3), 1373-1382.

McCambridge J, Winstock A and Hunt N (2006) 5-Year trends in use of hallucinogens and other adjunct drugs among UK dance drug users. Addiction 100:1140-49.

Mixmag1 http://www.mixmag.net/words/features/mixmags-global-drug-survey-the-results

Morgan, C. J., \& Curran, H. V. (2012). Ketamine use: a review. Addiction,107(1), 27-38.

Morgenstern J, Langenbucher J And Labouvie EW (1994) The generalizability of the dependence syndrome across substances: an examination of some properties of the proposed DSM-IV dependence criteria. Addiction 89(9): 1105-1113.

Nutt, D. J., King, L. A., \& Phillips, L. D. (2010). Drug harms in the UK: a multicriteria decision analysis. The Lancet, 376(9752), 1558-1565.

Rose, S. R., Poklis, J. L., \& Poklis, A. (2013). A case of 25I-NBOMe (25-I) intoxication: a new potent 5-HT2A agonist designer drug. Clinical toxicology,51(3), 174-177.

Schulhofer, S. J. (1994). Solving the Drug Enforcement Dilemma: Lessons from Economics. $U$. Chi. Legal F., 207.

Website 1 http://www.benzo-fury.me.uk/index/176 157

Website 2 http://www.lizardlabs.co.uk/ 
Winstock AR and Barratt MJ (2013) Synthetic cannabis: A comparison of patterns of use and effect profile with natural cannabis in a large global sample. Drug and alcohol dependence.

Winstock AR, Griffiths P and Stewart D (2001) Drugs and the dance music scene: a survey of current drug use patterns among a sample of dance music enthusiasts in the UK. Drug And Alcohol Dependence 64(1): 9-17.

Winstock AR, Mitcheson LR, Deluca P, et al. (2011) Mephedrone, new kid for the chop? Addiction 106(1), 154-161.

Winstock AR, Mitcheson L, Gillatt DA, et al. (2012) The prevalence and natural history of urinary symptoms among recreational ketamine users. BJU international 110(11), 1762-1766.

Winstock, A., Mitcheson, L., \& Marsden, J. (2010). Mephedrone: still available and twice the price. The Lancet, 376(9752), 1537.

Zuba, D., Sekuła, K., \& Buczek, A. (2012). 25C-NBOMe-New potent hallucinogenic substance identified on the drug market. Forensic Science International. 